\title{
OPEN NIR-chemometric approaches for evaluating carbonization characteristics of hydrothermally carbonized lignin
}

Sung-Wook Hwang ${ }^{1}$, Un Taek Hwang ${ }^{2}$, Kyeyoung Jo ${ }^{2}$, Taekyeong Lee ${ }^{1}$, Jinseok Park ${ }^{3}$, Jong-Chan $\mathrm{Kim}^{3}$, Hyo Won Kwak ${ }^{1,2,3}$, In-Gyu Choi ${ }^{1,2,3}$ \& Hwanmyeong $\mathrm{Yeo}^{1,2,3 凶}$

The aim of this study is to establish prediction models for the non-destructive evaluation of the carbonization characteristics of lignin-derived hydrochars as a carbon material in real time. Hydrochars are produced via the hydrothermal carbonization of kraft lignins for $1-5 \mathrm{~h}$ in the temperature range of $175-250^{\circ} \mathrm{C}$, and as the reaction severity of hydrothermal carbonization increases, the hydrochar is converted to a more carbon-intensive structure. Principal component analysis using near-infrared spectra suggests that the spectral regions at 2132 and $2267 \mathrm{~nm}$ assigned to lignins and $1449 \mathrm{~nm}$ assigned to phenolic groups of lignins are informative bands that indicate the carbonization degree. Partial least squares regression models trained with near-infrared spectra accurately predicts the carbon content, oxygen/carbon, and hydrogen/carbon ratios with high coefficients of determination and low root mean square errors. The established models demonstrate better prediction than ordinary least squares regression models.

Lignin is an abundant, naturally occurring organic material. Increasing environmental restrictions and fossil fuel prices have rendered lignocellulosic biomass an important source of renewable materials. Most of the currently commercialized carbon materials are coal based, and carbon dioxide and toxic gases generated during mining and refining can result in climate change, in addition to environmental pollution. By contrast, lignin is an ecofriendly and economical raw material that is mass produced as a byproduct of pulping in the paper industry. Lignins produced in industry are used primarily as a fuel for generating electricity and heat ${ }^{1}$. However, recent studies have been conducted to produce various high-value-added products from lignins, such as carbon fibers, activated carbon, vanillin, phenol derivatives, and phenolic resins ${ }^{2-5}$.

Hydrothermal carbonization (HTC), one of the major approaches to utilizing lignin, is a thermochemical conversion process from biomass for producing coal-like products ${ }^{6}$. Compared with pyrolysis, which is another important category of biomass conversion, HTC offers the advantage of relatively low processing requirements, stability, and nontoxicity owing to its low process temperature $\left(180-250^{\circ} \mathrm{C}\right)$. Hydrochars produced by the HTC of lignin can be used in various applications, including lightweight polymer composites, absorbents, electrochemical devices, energy devices, batteries, and automotive ${ }^{1,7-9}$, not for low-cost fuels.

Although the carbonization characteristics of lignin-derived hydrochars must be evaluated, real-time measurements are not possible through conventional elemental analysis based on high-temperature combustion and gas chromatography. Owing to its advantages of fast and non-destructive measurements, simple sample preparation, and low cost ${ }^{10,11}$, near-infrared spectroscopy (NIRS) may be a promising alternative for overcoming the limitations of conventional methods. In combination with multivariate analysis, NIRS is suitable for physical and chemical analyses of wood ${ }^{12-15}$, as well as for wood identification ${ }^{16,17}$.

The aim of this study is to establish accurate models for predicting the carbonization characteristics of kraftlignin-derived hydrochars. The hydrochars were produced under various HTC conditions, and their elemental compositions were determined via elemental analysis. Principal component analysis (PCA) and partial least

\footnotetext{
${ }^{1}$ Research Institute of Agriculture and Life Sciences, Seoul National University, 1 Gwanak-ro, Gwanak-gu, Seoul 08826, Republic of Korea. ${ }^{2}$ Department of Forest Sciences, College of Agriculture and Life Sciences, Seoul National University, 1 Gwanak-ro, Gwanak-gu, Seoul 08826, Republic of Korea. ${ }^{3}$ Department of Agriculture, Forestry and Bioresources, College of Agriculture and Life Sciences, Seoul National University, 1 Gwanak-ro, Gwanak-gu, Seoul 08826, Republic of Korea. ${ }^{\square}$ email: hyeo@snu.ac.kr
} 


\begin{tabular}{|c|c|c|c|c|c|c|}
\hline \multicolumn{2}{|l|}{ Sample } & \multirow[b]{2}{*}{ C (wt\%) } & \multirow[b]{2}{*}{ H (wt\%) } & \multirow[b]{2}{*}{$\mathbf{N}(\mathbf{w t} \%)$} & \multirow[b]{2}{*}{$S(w t \%)$} & \multirow[b]{2}{*}{$\mathrm{O}^{\mathrm{a}}(\mathrm{wt} \%)$} \\
\hline Temp. $\left({ }^{\circ} \mathrm{C}\right)$ & Time (h) & & & & & \\
\hline \multicolumn{2}{|l|}{ Control } & 62.83 & 5.79 & 0.39 & 1.74 & 29.25 \\
\hline \multirow{4}{*}{175} & 1 & 65.36 & 5.66 & 0.46 & 1.29 & 27.23 \\
\hline & 2 & 65.76 & 5.65 & 0.40 & 1.24 & 26.95 \\
\hline & 3 & 65.73 & 5.64 & 0.41 & 1.20 & 27.02 \\
\hline & 5 & 65.82 & 5.63 & 0.41 & 1.21 & 26.93 \\
\hline \multirow{4}{*}{200} & 1 & 65.73 & 5.52 & 0.41 & 1.28 & 27.06 \\
\hline & 2 & 66.19 & 5.46 & 0.43 & 1.41 & 26.51 \\
\hline & 3 & 66.25 & 5.55 & 0.42 & 1.24 & 26.53 \\
\hline & 5 & 67.02 & 5.58 & 0.43 & 1.23 & 25.73 \\
\hline \multirow{4}{*}{225} & 1 & 67.24 & 5.58 & 0.43 & 1.13 & 25.62 \\
\hline & 2 & 67.43 & 5.58 & 0.42 & 1.13 & 25.44 \\
\hline & 3 & 67.44 & 5.48 & 0.41 & 1.11 & 25.56 \\
\hline & 5 & 68.11 & 5.51 & 0.43 & 1.12 & 24.82 \\
\hline \multirow{4}{*}{250} & 1 & 68.23 & 5.48 & 0.45 & 1.12 & 24.73 \\
\hline & 2 & 68.64 & 5.54 & 0.47 & 0.92 & 24.43 \\
\hline & 3 & 69.12 & 5.47 & 0.49 & 0.92 & 24.00 \\
\hline & 5 & 69.37 & 5.38 & 0.49 & 0.87 & 23.89 \\
\hline
\end{tabular}

Table 1. Elemental composition of kraft-lignin-derived hydrochars. ${ }^{a} \mathrm{O}(\mathrm{wt} \%)=100-(\mathrm{C}+\mathrm{H}+\mathrm{N}+\mathrm{S})(\mathrm{wt} \%)$.

squares regression (PLSR) were employed to analyze the carbonization characteristics from near infrared (NIR) spectra obtained from the hydrochars and to establish prediction models, respectively.

\section{Results and discussion}

Elemental analysis. The elemental compositions of the hydrochars produced by HTC are listed in Table 1. The carbon content ( $\mathrm{C} \mathrm{wt} \%$ ) of the control (uncarbonized) sample was $62.83 \mathrm{wt} \%$, and this value increased with the HTC temperature and residence time. The HTC process at $175^{\circ} \mathrm{C}$ for $1 \mathrm{~h}$ increased the carbon content by approximately $2.5 \mathrm{wt} \%$ compared with the control, and the process at $250{ }^{\circ} \mathrm{C}$ for $5 \mathrm{~h}$ increased by approximately $6.5 \mathrm{wt} \%$. As the HTC temperature and residence time increased, i.e., as the reaction severity increased, more carbon-intensive hydrochars were produced.

As shown in Fig. 1a, the carbon content increased logarithmically with the residence time at each temperature. This suggests that temperature imposes a more prominent effect on the carbon content than the residence time in the HTC of lignin. The van Krevelen diagram (Fig. 1b), which shows the changes in the oxygen/carbon $(\mathrm{O} / \mathrm{C})$ and hydrogen/carbon $(\mathrm{H} / \mathrm{C})$ ratios, shows the formation of a carbon-intensive structure via HTC. As the reaction severity increased, both $\mathrm{O} / \mathrm{C}$ and $\mathrm{H} / \mathrm{C}$ decreased. This is because $\mathrm{HTC}$ is an exothermic process that reduces both the oxygen and hydrogen contents of the feed via dehydration and oxidation ${ }^{6,18,19}$.

Spectral characteristics of HTC lignin. Figure 2 shows the original NIR spectra and the second-derivative spectra of hydrochars in the spectral region of 1250-2300 $\mathrm{nm}$. In the original spectra (Fig. 2a), it was difficult to distinguish the difference among the spectra by the HTC temperature, except that some peaks disappeared at $250{ }^{\circ} \mathrm{C}$. By contrast, in the second-derivative spectra (Fig. 2b), not only was the baseline of the spectrum adjusted, but the peaks were amplified, rendering the difference among the spectra with HTC temperatures more evident. Some differences were observed at wavelengths of 1449, 1685, 1927, and $2132 \mathrm{~nm}$. These bands, except for those at $1927 \mathrm{~nm}$ assigned to water ${ }^{20}$, were associated with lignin. The bands at 1449, 1685, and $2132 \mathrm{~nm}$ were assigned to the phenolic group, aromatic ring associated, and lignin, respectively ${ }^{21-24}$.

PCA. Figure 3 shows a two-dimensional scatter plot of scores and loadings for the first two principal components (PCs) from the PCA of the second-derivative NIR spectra. The first two PCs constituted $96 \%$ of the total variance (Fig. 3a). In the plot, the scores for each HTC temperature were segmented into clusters. Because the scores for each HTC temperature were primarily aligned along the PC1 axis, it was discovered that this component contained information regarding the reaction severity, whereas PC2 and PC1 contained information that can determine whether HTC occurred in lignin.

In the PC loading plot (Fig. 3b), the two PCs indicated high loading values in the bands related to lignin, and among them, PC1 showed the highest values at 2132 and $2267 \mathrm{~nm}$, both of which were assigned to lignin ${ }^{23,24}$. As shown from the second-derivative NIR spectra in Fig. 2b, the hydrochars and control indicated a clear spectral difference at 2132 and $2267 \mathrm{~nm}$, where a higher HTC temperature resulted in a higher peak. PC2 indicated a relatively high loading at $1449 \mathrm{~nm}$, which was assigned to the phenolic groups of lignin. It appeared that as the HTC temperature increased, the number of phenolic groups decreased, thereby increasing the carbon content. A decrease in the aromatic structure as the reaction severity increases has been reported in natural and HTC coals ${ }^{25}$. 

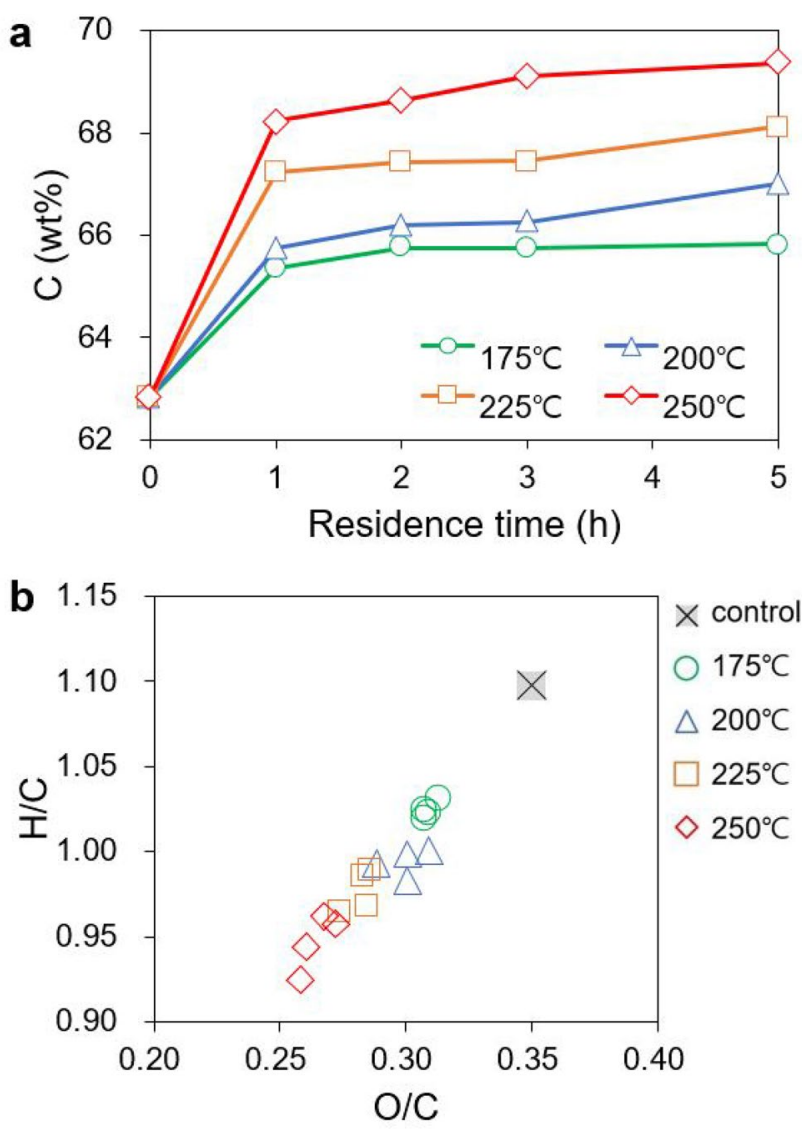

Figure 1. Carbonization characteristics of lignin-derived hydrochars. (a) Changes in carbon content of lignin samples with HTC temperature and residence time, and (b) its van Krevelen diagram, a plot of atomic O/C vs. atomic $\mathrm{H} / \mathrm{C}$.
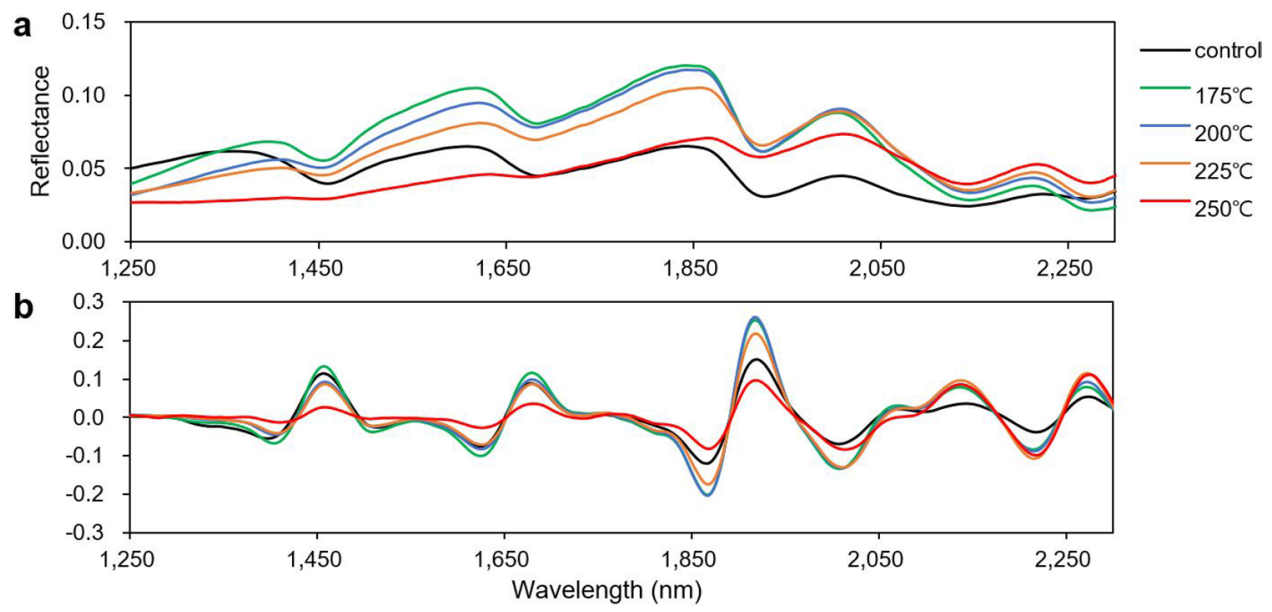

Figure 2. Original NIR spectra (a) and second-derivative spectra (b) with 1250-2300 nm region for hydrothermally carbonized kraft lignin and control samples.

Regression models. Regression models were established to predict the carbonization characteristics of kraft-lignin-derived hydrochars produced via HTC. Figure 4 shows the results of the PLSR models trained with the second-derivative NIR spectra for $\mathrm{C}(\mathrm{wt} \%), \mathrm{O} / \mathrm{C}$, and $\mathrm{H} / \mathrm{C}$ predictions. The models predicted $\mathrm{C}(\mathrm{wt} \%), \mathrm{O} / \mathrm{C}$, and $\mathrm{H} / \mathrm{C}$ with high coefficients of determination $\left(R^{2}\right)$ of $0.976,0.964$, and 0.984 , respectively, demonstrating that PLSR with NIRS is promising for predicting the carbonization characteristics of hydrochars. 

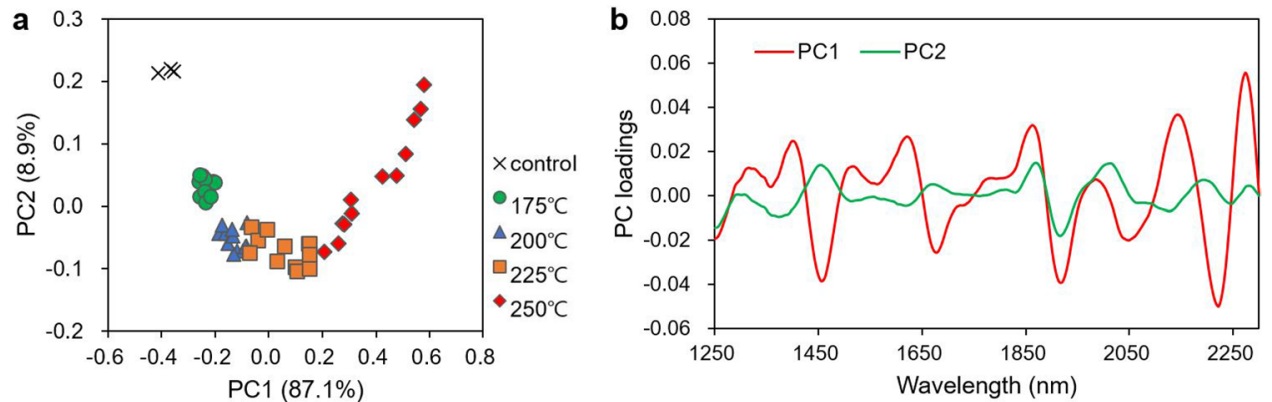

Figure 3. PCA score plot on first two PCs in second-derivative NIR spectra (a) and loadings of PCs (b). In score plot (a), percentages in parentheses of $\mathrm{x}$ - and $\mathrm{y}$-axis titles are those of explained variables of corresponding PC.
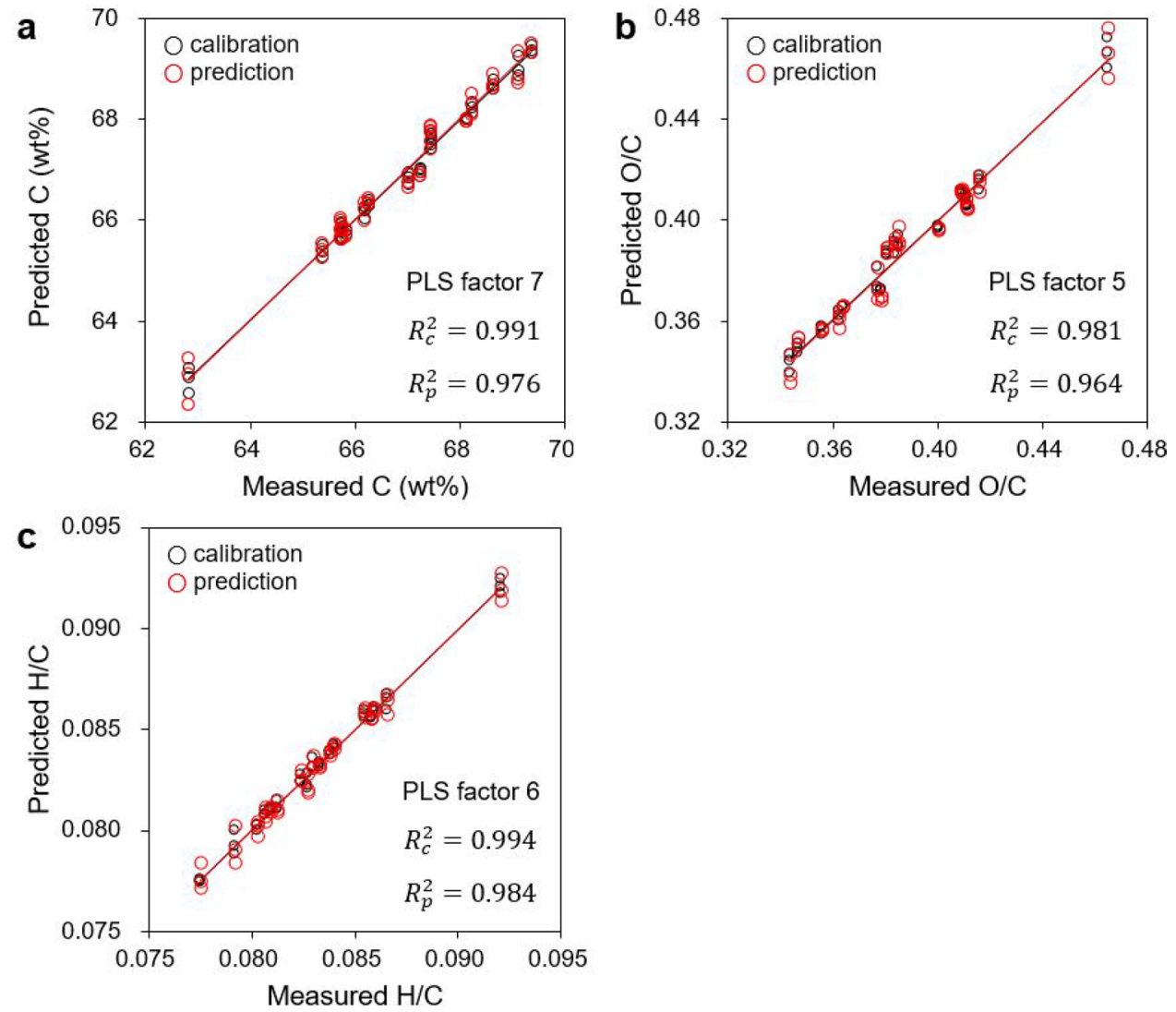

Figure 4. Scatter plots of prediction results for carbon content (a), O/C (b), and H/C (c) by PLSR models trained with second-derivative NIR spectra. $R_{\mathrm{c}}^{2}$ coefficient of determination for calibration, $R_{\mathrm{p}}^{2}$ coefficient of determination for prediction.

In this study, the spectral region of $1250-2300 \mathrm{~nm}$ was selected from the original range of $870-2500 \mathrm{~nm}$ and used to analyze the carbonization characteristics and establish prediction models. Although the unselected regions were noisy, some informative spectral bands related to lignin were present within these regions. Therefore, to determine whether the selection of the spectral region was appropriate, the prediction performance of the PLSR models in the second-derivative spectra with a full range of 870-2500 $\mathrm{nm}$ was investigated. As shown in Fig. 5, the selected spectral region $(1250-2300 \mathrm{~nm})$ yielded higher $R^{2}$ values than those of the full spectral region $(870-2500 \mathrm{~nm})$ for all carbonization characteristics, thereby justifying the spectral selection.

Spectrum pretreatment contributed insignificantly to the improvement in the prediction performance of the PLSR models. Models trained with the second-derivative NIR spectra produced higher $R^{2}$ values and lower root mean square errors (RMSEs) as well as reduced numbers of optimal partial least squares (PLS) factors than those trained with the original spectra (Table 2). 


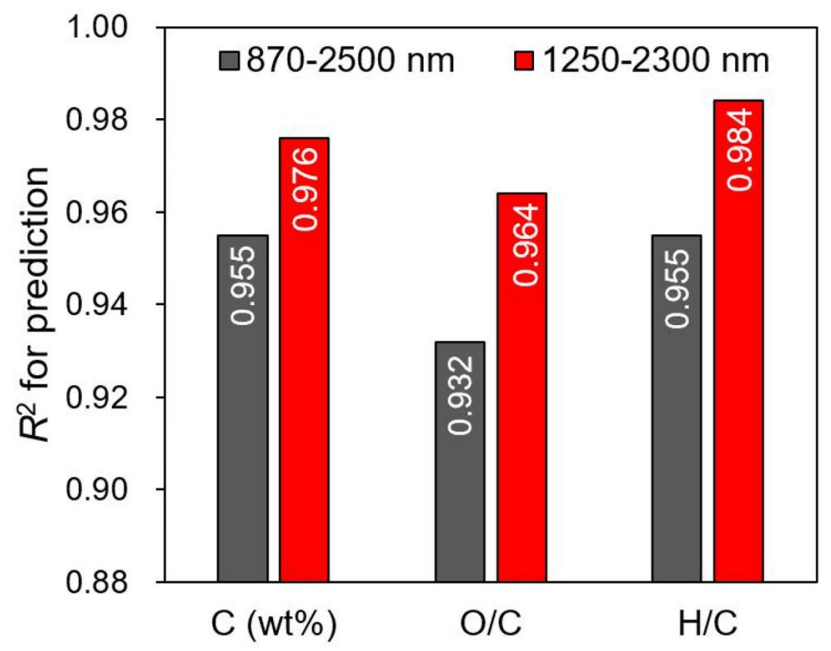

Figure 5. Comparison of coefficients of determination for prediction of PLSR models established in NIR spectral region of 870-2500 $\mathrm{nm}$ (full range) and 1250-2300 $\mathrm{nm}$ (selected in this study).

\begin{tabular}{|c|c|c|c|c|c|c|c|c|c|c|}
\hline \multirow[b]{3}{*}{ Output variable } & \multirow[b]{3}{*}{ Spectrum pretreatment } & \multicolumn{5}{|l|}{ PLSR } & \multicolumn{4}{|l|}{ OLSR } \\
\hline & & \multirow[b]{2}{*}{ PLS factors } & \multicolumn{2}{|c|}{ Calibration } & \multicolumn{2}{|c|}{ Prediction } & \multicolumn{2}{|c|}{ Calibration } & \multirow{2}{*}{$\begin{array}{l}\text { Prediction } \\
R_{\mathrm{p}}^{2}\end{array}$} & \multirow[b]{2}{*}{ RMSEP } \\
\hline & & & $R_{c}^{2}$ & RMSEC & $R_{\mathrm{p}}^{2}$ & RMSEP & $R_{\mathrm{c}}^{2}$ & RMSEC & & \\
\hline \multirow{2}{*}{ C (wt\%) } & Original & 8 & 0.987 & 0.1840 & 0.973 & 0.2590 & 0.999 & 0.0003 & 0.953 & 0.3440 \\
\hline & 2nd derivative & 7 & 0.991 & 0.1486 & 0.976 & 0.2461 & 0.999 & \begin{tabular}{|l|}
0.0003 \\
\end{tabular} & 0.940 & 0.3885 \\
\hline \multirow{2}{*}{$\mathrm{O} / \mathrm{C}$} & Original & 6 & 0.974 & 0.0048 & 0.963 & 0.0057 & 0.999 & 0.0003 & 0.907 & 0.0091 \\
\hline & 2nd derivative & 5 & 0.981 & 0.0041 & 0.964 & 0.0056 & 0.999 & 0.0003 & 0.874 & 0.0106 \\
\hline \multirow{2}{*}{$\mathrm{H} / \mathrm{C}$} & Original & 7 & 0.990 & 0.0003 & 0.984 & 0.0004 & 0.992 & 0.0003 & 0.966 & 0.0006 \\
\hline & 2nd derivative & 6 & 0.994 & 0.0003 & 0.984 & 0.0004 & 0.992 & 0.0003 & 0.912 & 0.0010 \\
\hline
\end{tabular}

Table 2. Prediction performance for carbonization characteristics of PLSR models in NIR spectra with 1250$2300 \mathrm{~nm}$ region and comparison with OLSR models. PLSR partial least squares regression, OLSR ordinary least squares regression, $R_{c}^{2}$ coefficient of determination for calibration, $R_{p}^{2}$ coefficient of determination for prediction, RMSEC root mean square error of calibration, RMSEP root mean square error of prediction.

To evaluate the prediction performance of the PLSR models, ordinary least squares regression (OLSR) models trained with identical spectral data were developed, and their performance comparisons are listed in Table 2. The PLSR models outperformed the OLSR models in predicting all the carbonization characteristics tested. In contrast to OLSR, which used all of the selected NIR spectral regions as input variables (165-dimensional vector), PLSR yielded better performances, even from variables (PLS factors) scaled down to eight or fewer. We attribute this result to the presence of non-informative or non-contributing spectral bands for the prediction in the NIR spectra. In contrast to spectral bands assigned to the phenolic group (1449 nm), aromatic ring associated $(1685 \mathrm{~nm})$, and lignin $(2132$ and $2267 \mathrm{~nm})$, bands assigned to water $(1927 \mathrm{~nm})$ and non-lignin-related components lack direct relevance to the HTC process. In other words, the new variables created via dimensional reduction by PLS sufficiently preserved the variance of the original data and simultaneously revealed the unique features of each observation. For data with a high correlation among input variables, i.e., high multicollinearity, it has been reported that PLSR provided more stable results than OLSR ${ }^{26}$.

The PLSR model combined with NIRS is a promising approach for predicting the carbonization characteristics of lignin-derived hydrochars produced via HTC, which allows for non-destructive analysis.

\section{Conclusions}

As the reaction severity in HTC increased, more carbon-intensive hydrochars were produced. NIRS is an effective tool for capturing information regarding the reaction severity, and PCA provided insights into some of the spectral regions that contained the information thereof. The PLSR models established with NIR data accurately predicted the carbonization characteristics of hydrochars, and the selection of the spectral region and spectral pretreatment by the second derivative improved the performance of the models. The results of this study demonstrated that the PLSR model combined with NIRS is a promising approach for the rapid and non-destructive prediction of the carbonization characteristics of kraft-lignin-derived hydrochars produced via HTC. The operational simplicity and speed of NIRS allow for real-time measurements; thus, this method can be applied 
to industry as an on-line measurement system in the HTC process or an at-line system if additional sample conditioning is required.

\section{Materials and methods}

Sample preparation. Hydrochars were produced by the HTC of kraft lignin, a byproduct of industrialscale pulping for producing bleached hardwood pulp. In cooking and bleaching, a strong alkaline white liquor comprising sodium hydroxide, sodium sulfide, and chlorine dioxide is used. Suspensions of $5.6 \mathrm{~g}$ of lignin powder and distilled water (140 $\mathrm{mL}$ of distilled water, i.e., a solid-to-liquid ratio of $2 / 50$ ), were hydrothermally carbonized.

Hydrothermal carbonization. To produce hydrochars from lignin and to investigate the effects of temperature and reaction time on the carbonization characteristics of lignin in HTC, the suspension was placed in a glass liner and heated for $1,2,3$, and $5 \mathrm{~h}$ in a heating mantle set at temperatures of $175^{\circ} \mathrm{C}, 200{ }^{\circ} \mathrm{C}, 225^{\circ} \mathrm{C}$, and $250{ }^{\circ} \mathrm{C}$, respectively. The heating rate was $2.6^{\circ} \mathrm{C} / \mathrm{min}$, and the reaction time refers to the period in which the temperature is maintained constant after reaching each set temperature. At the end of the target reaction time, heating was stopped, and the reaction vessel was stored at room temperature for natural cooling. Subsequently, hydrochars, i.e., solid residues formed via HTC, were vacuum filtered and dried in an oven at $60^{\circ} \mathrm{C}$ for $48 \mathrm{~h}$. The dried samples were pulverized and then humidified at $25^{\circ} \mathrm{C}$ and $60 \%$ relative humidity for elemental analysis and NIRS measurements.

Elemental analysis. The carbonization characteristics of the hydrochars were investigated by quantifying C, H, N, and S using an elemental analyzer (Flash 2000, Thermo Fisher Scientific, Waltham, MA, USA). The C, $\mathrm{H}, \mathrm{N}$, and $\mathrm{S}$ in the sample reacted with pure oxygen at a high temperature of $850-950{ }^{\circ} \mathrm{C}$ and converted into $\mathrm{CO}_{2}$, $\mathrm{H}_{2} \mathrm{O}, \mathrm{N}_{2}$, and $\mathrm{SO}_{2}$. These gases were purified, passed through a gas chromatography column, separated, and then quantified using a thermal conductivity detector.

NIRS. NIR spectra were obtained from the HTC lignin and control samples using an NIR spectrometer (NIR Quest, Ocean Insight, Orlando, FL, USA) equipped with a tungsten-halogen light source and a reflection probe (QR400-7-VIS-BX, Ocean Insight, Orlando, FL) with an outer diameter of $6.35 \mathrm{~mm}$ and a core diameter of $0.4 \mathrm{~mm}$. The spectra were collected at a wavelength of $870-2500 \mathrm{~nm}$ and an optical resolution of $6.6 \mathrm{~nm}$; subsequently, 16 scans were averaged per scan. Three spectra were obtained per sample; hence, 51 spectra were obtained from the prepared samples. Prior to performing the multivariate analysis, the original NIR spectrum was normalized and second derivatized via Savitzky-Golay filter smoothing ${ }^{27}$ to 11 points using the fifth-order function. As regions under $1250 \mathrm{~nm}$ and beyond $2300 \mathrm{~nm}$ were noisy, the spectral range of $1250-2300 \mathrm{~nm}$ was used for the multivariate analysis.

Multivariate analysis. PCA was performed to analyze the chemical changes in the lignin samples caused by HTC. PCA transformed the NIR data with a spectral range of 1250-2300 nm into a new orthogonal coordinate system comprising six components. The carbonization characteristics of the lignin and the spectral regions affecting it were investigated by analyzing the scores and loadings of the PCs.

PLSR was employed to establish models for predicting the carbonization characteristics of the lignin via HTC. Models that output the carbon content $(\mathrm{C} w \mathrm{t} \%), \mathrm{O} / \mathrm{C}$ ratio, and $\mathrm{H} / \mathrm{C}$ ratio were designed using NIR spectral data as input variables. The optimal number of latent variables for the PLSR models was obtained using the leave-oneout cross-validation technique ${ }^{28}$. The performance of the PLSR models was evaluated using $R^{2}$ and the RMSE for the calibration and prediction sets.

$$
\begin{gathered}
R^{2}=1-\left(\sum_{i}\left(y_{i}-\hat{y}_{i}\right)^{2} / \sum_{i}\left(y_{i}-\mu\right)^{2}\right), \\
\text { RMSE }=\sqrt{\frac{1}{n} \sum_{i=1}^{n}\left(\hat{y}_{i}-y_{i}\right)^{2},}
\end{gathered}
$$

where $y_{i}$ and $\hat{y}_{i}$ are the measured and predicted values of the $i$-th observation, respectively, $\mu$ is the overall mean, and $n$ is the number of observations in the calibration and prediction sets. The PCA and PLSR models were implemented using Python 3.8, with programming libraries for multivariate analysis.

\section{Data availability}

The datasets generated and/or analyzed during the current study are available from the corresponding author upon reasonable request.

Received: 10 May 2021; Accepted: 2 August 2021

Published online: 20 August 2021

\section{References}

1. Luo, H. \& Abu-Omar, M. M. Chemicals from lignin. In Encyclopedia of Sustainable Technologies (ed. Abraham, M.) 573-585 (Elsevier, 2017). 
2. Agrawal, A., Kaushik, N. \& Biswas, S. Derivatives and applications of lignin-an insight. Sci. Technol. J. 1, 30-36 (2014).

3. Mandlekar, N. et al. An overview on the use of lignin and its derivatives in fire retardant polymer systems. In Lignin: Trends and Applications (ed. Poletto, M.) 207-231 (InTech, 2018)

4. Kim, K. H., Kim, J. Y., Kim, C. S. \& Choi, J. W. Pyrolysis of lignin obtained from cinnamyl alcohol dehydrogenase (CAD) downregulated Arabidopsis thaliana. J. Korean Wood Sci. Technol. 47, 442-450 (2019).

5. Kleinert, M. \& Barth, T. Phenols from lignin. Chem. Eng. Technol. 31(5), 736-745 (2008).

6. Funke, A. \& Ziegler, F. Hydrothermal carbonization of biomass: A summary and discussion of chemical mechanisms for process engineering. Biofuels Bioprod. Biorefin. 4(2), 160-177 (2010).

7. Feng, Q., Chen, F. \& Wu, H. Preparation and characterization of a temperature-sensitive lignin-based hydrogel. BioResources 6, 4942-4952 (2011).

8. Puziy, A. M., Poddubnaya, O. I. \& Sevastyanova, O. Carbon materials from technical lignins: Recent advances. Top. Curr. Chem. 376, 33. https://doi.org/10.1007/s41061-018-0210-7 (2018).

9. Aro, T. \& Fatehi, P. Production and application of lignosulfonates and sulfonated lignin. Chemsuschem 10(9), 1861-1877 (2017).

10. Roggo, Y. et al. A review of near infrared spectroscopy and chemometrics in pharmaceutical technologies. J. Pharm. Biomed. Anal. 44(3), 683-700 (2007).

11. Tsuchikawa, S. A review of recent near infrared research for wood and paper. Appl. Spectrosc. Rev. 42(1), 43-71 (2007).

12. Zhou, C., Jiang, W., Via, B. K., Fasina, O. \& Han, G. Prediction of mixed hardwood lignin and carbohydrate content using ATRFTIR and FT-NIR. Carbohydr. Polym. 121, 336-341 (2015).

13. Raymond, C. A. \& Schimleck, L. R. Development of near infrared reflectance analysis calibrations for estimating genetic parameters for cellulose content in Eucalyptus globulus. Can. J. For. Res. 32(1), 170-176 (2002).

14. Via, B. K., Shupe, T. F., Groom, L. H., Stine, M. \& So, C. L. Multivariate modelling of density, strength and stiffness from near infrared spectra for mature, juvenile and pith wood of longleaf pine (Pinus palustris). J. Near Infrared Spectrosc. 11(5), 365-378 (2003).

15. Yang, S. Y. et al. Partial least squares analysis on near-infrared absorbance spectra by air-dried specific gravity of major domestic softwood species. J. Korean Wood Sci. Technol. 45, 399-408 (2017).

16. Horikawa, Y., Mizuno-Tazuru, S. \& Sugiyama, J. Near-infrared spectroscopy as a potential method for identification of anatomically similar Japanese diploxylons. J. Wood Sci. 61(3), 251-261 (2015).

17. Hwang, S. W., Horikawa, Y., Lee, W. H. \& Sugiyama, J. Identification of Pinus species related to historic architecture in Korea using NIR chemometric approaches. J. Wood Sci. 62(2), 156-167 (2016).

18. Ross, D. S., Loo, B. H., Tse, D. S. \& Hirschon, A. S. Hydrothermal treatment and the oxygen functionalities in Wyodak coal. Fuel 70, 289-295 (1991).

19. Peterson, A. A. et al. Thermochemical biofuel production in hydrothermal media: A review of sub- and supercritical water technologies. Energy Environ. Sci. 1(1), 32-65 (2008).

20. Workman, J. Jr. \& Weyer, L. Practical Guide and Spectral Atlas for Interpretive Near-Infrared Spectroscopy (CRC Press, 2007).

21. Fackler, K. \& Schwanninger, M. Polysaccharide degradation and lignin modification during brown rot of spruce wood: A polarised Fourier transform near infrared study. J. Near Infrared Spectrosc. 18(6), 403-416 (2010).

22. Bailleres, H., Davrieux, F. \& Ham-Pichavant, F. Near infrared analysis as a tool for rapid screening of some major wood characteristics in a eucalyptus breeding program. Ann. For. Sci. 59(5-6), 479-490 (2002).

23. Michell, A. J. \& Schimleck, L. R. NIR spectroscopy of woods from Eucalyptus globulus. Appita J. 49, 23-26 (1996).

24. Schwanninger, M., Rodrigues, J. C. \& Fackler, K. A review of band assignments in near infrared spectra of wood and wood components. J. Near Infrared Spectrosc. 19(5), 287-308 (2011).

25. Sugimoto, Y. \& Miki, Y. Chemical structure of artificial coals obtained from cellulose, wood and peat. In Proceedings of the 9th International Conference on Coal Science 187-190, (1997).

26. Farahani, H. A., Rahiminezhad, A., Same, L. \& Immannezhad, K. A comparison of partial least squares (PLS) and ordinary least squares (OLS) regressions in predicting of couples mental health based on their communicational patterns. Proced. Soc. Behav. Sci. 5, 1459-1463(2010).

27. Savitzky, A. \& Golay, M. J. E. Smoothing and differentiation of data by simplified least squares procedures. Anal. Chem. 36(8), 1627-1639 (1964).

28. Hastie, T., Tibshirani, R. \& Friedman, J. The Elements of Statistical Learning: Data Mining, Inference, and Prediction (Springer, 2009).

\section{Acknowledgements}

This study was supported by the Korea Forestry Promotion Institute through the R\&D Program for Forest Science Technology, funded by the Korea Forest Service (Project No. 2020215D10-2122-AC01). The authors thank MOORIM P\&P Co., Ltd. for providing the kraft lignin. We would like to thank Editage (www.editage.co.kr) for English language editing.

\section{Author contributions}

S.H. was the major contributor of this study and wrote the manuscript. U.H., K.J., T.L., J.P., and J.K. contributed to sample preparation and data analysis. H.K., I.C., and H.Y. conceived the original ideas. H.Y. edited the manuscript and supervised the study. All authors have read and approved the final manuscript.

\section{Competing interests}

The authors declare no competing interests.

\section{Additional information}

Correspondence and requests for materials should be addressed to H.Y.

Reprints and permissions information is available at www.nature.com/reprints.

Publisher's note Springer Nature remains neutral with regard to jurisdictional claims in published maps and institutional affiliations. 
(c) (i) Open Access This article is licensed under a Creative Commons Attribution 4.0 International cc) License, which permits use, sharing, adaptation, distribution and reproduction in any medium or format, as long as you give appropriate credit to the original author(s) and the source, provide a link to the Creative Commons licence, and indicate if changes were made. The images or other third party material in this article are included in the article's Creative Commons licence, unless indicated otherwise in a credit line to the material. If material is not included in the article's Creative Commons licence and your intended use is not permitted by statutory regulation or exceeds the permitted use, you will need to obtain permission directly from the copyright holder. To view a copy of this licence, visit http://creativecommons.org/licenses/by/4.0/.

(C) The Author(s) 2021 